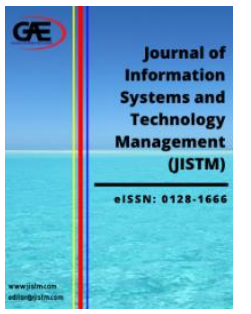

\author{
JOURNAL OF INFORMATION \\ SYSTEM AND TECHNOLOGY \\ MANAGEMENT (JISTM) \\ WWW.jistm.com
}

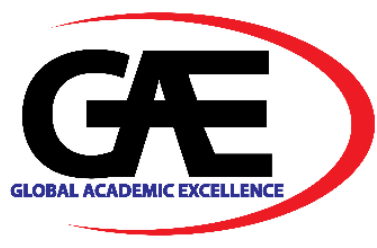

\title{
A REVIEW ON HUMAN ERROR IN MALAYSIA MANUFACTURING INDUSTRIES
}

\author{
Jian Ai Yeow ${ }^{1 *}$, Poh Kiat $\mathrm{Ng}^{2}$, Hen Toong Tai ${ }^{3}$, Mei Min Chow ${ }^{4}$ \\ 1 Faculty of Business, Multimedia University, Melaka, Malaysia \\ Email: jayeow@mmu.edu.my \\ 2 Faculty of Engineering and Technology, Multimedia University, Melaka, Malaysia \\ Faculty of Business, Multimedia University, Melaka, Malaysia \\ Faculty of Business, Multimedia University, Melaka, Malaysia \\ Corresponding Author
}

\section{Article Info:}

Article history:

Received date: 13.07 .2020

Revised date: 10.08 .2020

Accepted date: 30.09 .2020

Published date: 01.12.2020

\section{To cite this document:}

Yeow, J. A., Ng, P. K., Tai, H. T., \& Chow, M. M. (2020). A Review on Human Error in Malaysia Manufacturing Industries. Journal of Information System and Technology Management, 5 (19), 01-13.

DOI: $10.35631 /$ JISTM.519001.

This work is licensed under CC BY 4.0

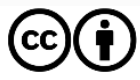

\begin{abstract}
:
Human error is a serious concern in manufacturing industries. It affects product error and liability and even leads to workplace injuries or fatalities. Malaysia has recorded a worrying figure of workplace accidents and injuries. In 2018 alone, there were more than 2700 workplace accidents which led to disabilities and death. A workplace accident would result in a no-win situation for a company. Manufacturing sectors in Malaysia make the highest claims from the total cost of accidents and injuries. The Department of Occupational Safety and Health (DOSH) in Malaysia also imposes a fine for companies who breach safety and health regulations in the workplace. Inspections are carried out to ensure that manufacturers obey the rules of occupational safety and health $(\mathrm{OSH})$, and fined for being errant employers. However, these penalisations are often due to the negligence and lack of awareness among employers and employees. Hence, it is of interest for researchers to identify the root causes of human error among manufacturing industries in Malaysia. This review highlights the common causes of workplace accidents and injuries in manufacturing through observation. Several well-known human error models since 1983 are also investigated. The potential outcome of this review is to improve OSH awareness among manufacturers for a more sustainable future in their business, employment, and social well-being.
\end{abstract}

\section{Keywords:}

Human Error, Manufacturing Industry, Occupational Safety And Health, Workplace Accidents And Injuries 


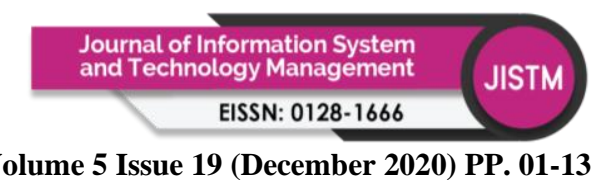

Volume 5 Issue 19 (December 2020) PP. 01-13 DOI: 10.35631/JISTM.519001

\section{Introduction}

Since early 90s century till now, Malaysia manufacturing industry is reported as one of the highest contributors of workplace accidents and injuries by DOSH. In December 2019, the local newspaper reported that a worker was killed by meat-mincing machine in Melaka, Malaysia while he was doing maintenance with three other workers when suddenly the machine turned on. In February 2020 as reported in DOSH, a worker died after getting stuck in a good hoist as the employer allowed the operating of unapproved hoist from DOSH. Additionally, in January 2020, a worker died due to employers failed to provide SOP (Standard Operating Procedures) and OSH (Occupational Safety and Health) system in the factory. It seems like every month, there is a minimum of 10 reported workplace fatalities cases involving locals or foreign workers. The DOSH urged employers to be more proactive in executing more initiatives to achieve zero-accident rate at the workplace. Despite of many governmental initiatives and efforts to prevent workplace accidents, the number is still at the alarming stage.

Human factors are the foundation of all causes of workplace accident and injury. Addressing the human error will reduce workplace accident. Realizing the importance of human error, this study aims to find the dimensions that contribute to human error in manufacturing industry and to determine the significant relationships of each variables. This research uses non-participative observation from 23 manufacturing companies after a multi-stage of cluster sampling. The root causes of workplace accidents and injuries were being reviewed through in-depth literature and model theories and then were being discussed and reviewed by the focus group panels. This study ends with discussion and interpretation of the research finding and provides some contribution and implication to manufacturing industry, employers, DOSH and even to the employees.

\section{Literature Review}

\section{Manufacturing Industry in Malaysia}

Generally, manufacturing is defined as the creation of goods for use or sale by using labour, machines, and tools. Manufacturing industry plays an important role in this world. Almost all developed and developing countries need manufacturing to enhance the country's trade and economic development. Malaysia is one of the top leading company for manufacturing electric and electronic products.

Sectors such as electrical and electronic related products, leather, textile and apparel, basic metal or steel products, manufacture of machinery, transport equipment and others are considered as non-resource-based industries. These sectors are value adding sectors in the manufacturing as it contributes more than 50 percent of total export in Malaysia (Yeow et al., 2017).

Due to the fast development of technology and globalization, manufacturing sectors had started to increase demand for better technology products and also enhancing the standard of living among the consumers. Manufacturing industries are working hard in producing more new product introduction, rapid technological innovation, unanticipated customer shift and latest information technology to cope with the changing market dynamic(Karim et al., 2008). Moreover, engineers in manufacturing are being more innovative in designing new products and tools. With that, studies related to manufacturing industry are needed as it helps to serve as inputs or information to the engineers. 
In additional, the manufacturing sector in Malaysia has grown up dramatically after 2000 and it is one of the largest employment sectors in Malaysia. This industry is also one of the largest export contributions where it helps to generate Malaysia's revenue. Therefore, it can be concluded that manufacturing industries is one the 'backbone' of Malaysia development and contributor to economic stability. However, the rapid development of employment and exporting in manufacturing sector could mean that there will be a big risk of workplace problem and accident.

Table 1: Occupational Accident by Sectors for the categories of Death, Permanent Disability and Non-Permanent Disability (Investigated by DOSH)

\begin{tabular}{|c|c|c|c|c|c|c|c|c|c|c|c|c|c|}
\hline Industry/year & 200 & 8008 & 0 & 201 & 0 & 201 & 201 & 20 & 201 & 201 & 2017 & 201 & 2019 \\
\hline Manufacturing & 2290 & 1775 & 157 & 1714 & 1649 & 172 & 1655 & 1667 & 2041 & 2315 & 2178 & 3228 & 4948 \\
\hline Mining and & 15 & 10 & 6 & 4 & 23 & 42 & 53 & 62 & 39 & 24 & 46 & 41 & 60 \\
\hline uarrying & & & & & & & & & & & & & \\
\hline Construction & 181 & 129 & 115 & 120 & 99 & 177 & 164 & 172 & 149 & 222 & 240 & 232 & 326 \\
\hline $\begin{array}{l}\text { Agricultural, } \\
\text { forestry, fishing \& } \\
\text { logging }\end{array}$ & 756 & 414 & 492 & 515 & 418 & 447 & 535 & 492 & 480 & 467 & 522 & 749 & 1176 \\
\hline Utility & 65 & 113 & 142 & 48 & 53 & 91 & 107 & 69 & 96 & 74 & 104 & 173 & 258 \\
\hline $\begin{array}{l}\text { Transport, storage \& } \\
\text { communication }\end{array}$ & 9 & 27 & 39 & 31 & 56 & 95 & 20 & 102 & 131 & 127 & 122 & 137 & 389 \\
\hline $\begin{array}{l}\text { Wholesales and } \\
\text { retailing }\end{array}$ & 15 & 2 & 0 & 0 & 17 & 69 & 78 & 83 & 108 & 111 & 97 & 73 & 87 \\
\hline Hotel and restaurants & 13 & 14 & 18 & 25 & 10 & 15 & 19 & 57 & 62 & 90 & 114 & 123 & 235 \\
\hline $\begin{array}{l}\text { Financial, real estate, } \\
\text { business service }\end{array}$ & 29 & 7 & 1 & 32 & 37 & 58 & 70 & 74 & 119 & 126 & 146 & 217 & 406 \\
\hline $\begin{array}{l}\text { Public sectors and } \\
\text { statutory bodies }\end{array}$ & 22 & 6 & 1 & 45 & 67 & 50 & 67 & 25 & 32 & 110 & 66 & 58 & 99 \\
\hline
\end{tabular}

Source: Compiled and adopted from Department of Occupational Safety and Health Statistics (year 2007-year 2019 in DOSH, 2020)

Table 1 shows that the occupational accidents by sectors for the categories of death, permanent disability and non-permanent disability. It is clearly shown that the manufacturing industry retains as the highest occupational accidents among all sectors throughout the period 2007 till now. According to Said, Halim and Said (2012), this rate can reflects that workers in the manufacturing sectors are exposed to higher accidental risks compared with other sectors. According to Zakaria et al. (2012), steps must be implemented for preventing workplace accidents and injuries. Zakaria et al. (2012) added that all accidents and injuries may have multiple causes and it is important to identify the causes of accidents. Hence, researchers from diverse areas are investigating the causes of workplace hazards. It was found that human error contributed more 90 percent of these workplace accidents and injuries (DiDomenico \& Nussbaum, 2008). Additionally, Williamson and Feyer (2000), stated that two out of three occupational accident are caused by human error. Therefore, according to Yeow et al.(2014) aims to explore the causes of human error in manufacturing are important to reduce the workplace accident and injuries. 


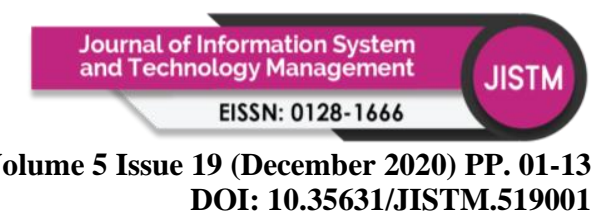

\section{Human Error}

Human errors are usually unavoidable in life (Saurin et al., 2004). It happens daily in workplace and may lead to either very low impact such as misplace of tools or even up to a very high impact such as fatal case. According to Liu, Hwang and Liu (2009), human error is the unsafe acts that carried out by the performer and may significantly bring negative impact to the workplace. Reason (1990) defined human error as "a generic term to encompass all those occasions in which a planned sequence of mental or physical activities fails to achieve its intended outcome, and when these failures cannot be attributed to the intervention of some chance agency". Therefore, in short human error can be considered as any mental or physical activities that fail to perform in the right way and lead to undesirable outcome.

According to Ruckart and Burgess (2007), nearly 90 percent of all workplace accidents come from human error and the percentage has increased four-fold between 1960s and 1990s. Additionally, a study in Finland had determined 84-94 percent of almost 300 hazardous events were caused by human error. Additionally, in Canada, 514 industrial accidents were due to human error. According to Malaysia DOSH websites (DOSH, 2020) in February 2020, there were 10 reported workplace accidents and 9 cases were due to employers and employees' negligence. Saurin et al (2008) stated that by identifying the causes of accidents, it may assist in the investigation process and preventing effort. With the supportive evidence and statistical data, many researchers had started their study on human error and foresee the consequences of human error in several industries. These researchers are not only focusing in developing effective methods of predicting and reducing human error, they also develop theoretical and methodological approaches that explained the correction of performance.

However, according to Reason (2017) to provide an effective correction of performance, more predictable varieties of human fallibility are needed to identify the root-cause of irrational where these error forms have their origins in fundamentally processes.

Table 2: Past Researchers' Studies on Human Error

\section{Findings}

Sully's Illusion in 1881: The first psychologist that classifies the broad spectrum of human error. A book called 'Illusion' was published and viewed that not only illusion of sense dealt with in treaties on psychological aspects; other form of error such as memory, belief, external perceptions and introspection are the fallibility of human (Reason, 2000).

Freudian Slip in 1896: Sigmund Freud described error in speech, memory or physical action that is happened due to an unconscious behaviour. (Gould, 1987)

Heath Bawden in 1900: American psychologist published 'A Study of Lapse' viewed that the kin of absentmindedness caused slips to take place and automatically involved involuntarily mistake that could not be controlled.(Ellis, 1900)

Bartlett's Schema in 1932: Bartlett did a 'War of the Ghost' experiment and found out that the longer-term memory or heavy mental stress, the more error will occur. (Carbon \& Albrecht, 2012) 


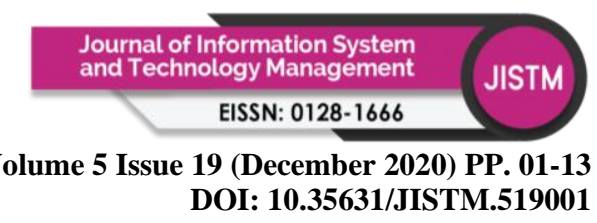

Fitts and Jones in 1947: Paul Fitts and Richard Jones are the ground researchers of human factors in aviation line, stated human error are systematically connected to features of people's tools, task and operating environment. (Dekker, 2013)

Edwards SHEL model in 1972: The model describes the relationship between humanmachine interaction that may cause error to occur. There are four categories of influences; software, hardware, environment condition and liveware (Molloy \& O’Boyle, 2005)

Rasmussen' s skill-rule-knowledge error in1983: Rasmussen's stated three levels of performance (skill-based, rule-based and knowledge based) correspond to the decrease level of familiarity with the environment or task that lead to error. (Rasmussen, 1983)

The Sweedish Studies by Allwood in 1983: investigation of error detection during problem solving. Error detected occurs during negative evaluation, which concluded that error occurs due to mismatch between stored representation of past and current observed situation. ( Reason, 2000)

The Italian Studies by Rizzo and his collaborators in 1986: examined the relationship between skill-rule-knowledge and self-monitoring detection processes. Most skill-based slip error occurred in the experiment (Reason, 2000) .

The Generic Error Modelling System (GEMS) by Reason in 1990: Based upon Rasmussen's framework, there are three types of error; skill-based are due to slips and lapse; rule-based are due to rules and regulation's mistake and knowledge-based are due to poor knowledge mistakes such as problem solving error, decision making error (Reason, 1990).

Swiss Cheese Model (SCM) by James Reason in 1990: Error occurs due to active failure and latent failure. There are five defences system; organisational factors, unsafe supervision, Precondition for Unsafe Act and unsafe activities resulting an adverse event (Reason, 1990).

Second Revision: SCM reduced the defences into three; organisation, task/environment and individual are the path that lead to failure (Reason, 2000).

Third Revision: The defences were removed and became the barriers, control, and safeguard of the system.

Behavioural Safety (BeSafe) Method: This model was developed by ergonomist at British Coal after SCM model and it is used to identify the potential human error audit using checklist, survey and task analysis (Benedyk \& Minister, 1998)

Besides studies from the overseas researchers, some Malaysian's researchers have also started to build interest in the studies of human error. For example, Ratnasingam et al. (2010) has conducted a primary research data to determine the factors affecting human error and the methods of data collection was interview methods. Yeow et al. (2014), Zakaria et al., (2012), Karim et al., (2008) and Surienty et al., (2011) had conducted several research on safety and health in manufacturing, workplace hazard and also highlighting the causes of workplace 


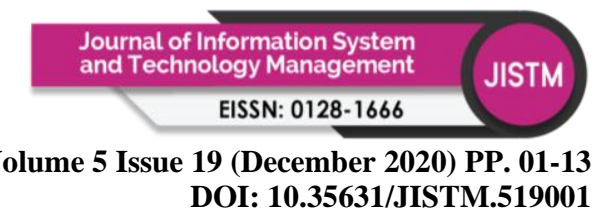

accidents and injuries. As mentioned earlier, accidents happen mainly due to human and it is the foundation study for identifying the causes of workplace hazard. Therefore, there is a need to study the causes of human error in workplace particularly in manufacturing industry.

\section{Theoretical Perspectives on Human Error}

According to Rasmussen (1983), there are three types of human error; skill-based (SB) error, rule-based $(\mathrm{RB})$ error and knowledge-based $(\mathrm{KB})$ error. Each of these types of human error determine different worker's job scope and activities. The causes of the error can be various as listed in Table 2.

The SB level represents the sensory and fine-motor performance during acts and error take place without conscious control. Both rules based and knowledge-based error are only called into play after the individual has become conscious of a problem. According to Rasmussen (1983), in most skilled sensory motor task, the body acts as a multivariable continuous control system that synchronizing movement with the behaviour of the environment.

Besides, Rasmussen's model is directed at the far more serious error that made by industrial especially during emergencies in hazardous process plants. This framework was originally developed from a protocol study of technician in electrical 'trouble-shooting' and it became a market standard within the system reliability community (Reason, 1990).

According to Rasmussen (1983), in order to understand human performance error, there is a need to define the categorised work conditions together with a qualitative framework that describe and define the relationship which is lacking in Rasmussen's study. Reason has also stated that Rasmussen's SRK based framework has justifiably a 'market standard' for human error study.

In manufacturing, problems happen at the initial stage, workers tend to face skill-based error. However, Reason (1990) mentioned that this model is used to explain the reason why error may happen in general workplace and pertaining other situational problem remain constant. In workplace, situational problems are unpredictable, therefore, there are some new studies on human error being developed by other researchers. Some models are being developed to predict or prevent the accidents in workplace based on situation such as unsafe act during performance. The Swiss Cheese Model is a popular model to determine the causation of human error.

The Swiss Chess model (SCM) was develop in early 1990 by James Reason. This model has been revised for 3 times by the same authors. However, Swiss Cheese Model One (Mark I) has been widely used by other researchers' model such as Human Factor Analysis and Classification System Causal Factors (HFACS) by Li and Harris. Till date, there are still lots of researches had been done to revisit the Swiss Cheese Model (Reason, 2016).

Accident causation may include 4 level of failure which are organizational influences, unsafe supervision, precondition for unsafe acts as well as personal causation. The model consists of 4 slices of 'cheese' which represents the level of failure and each individual' weaknesses are the 'holes' of cheese. The Figure 1 illustrated that the system as a whole might fail due to holes in each slices of cheese. 


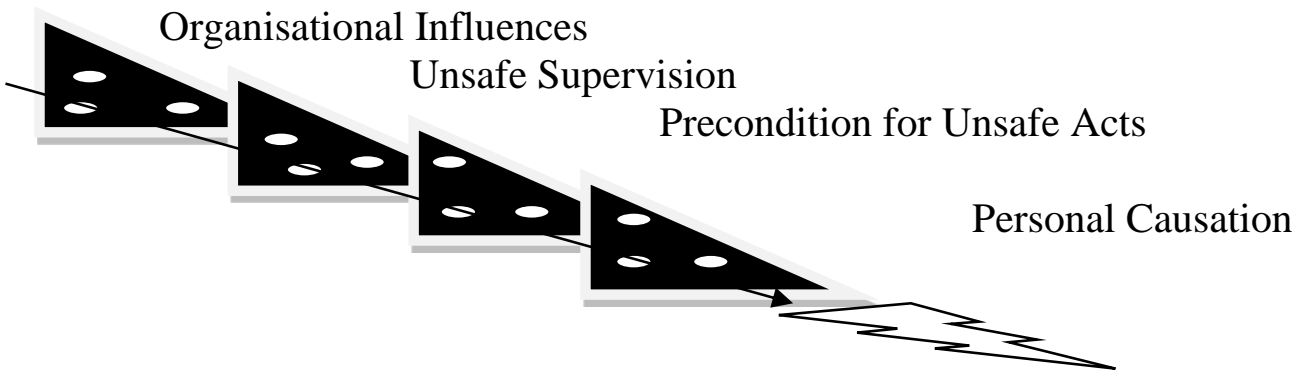

Figure 1: The Swiss Cheese Model

Sources: Adapted from Reason (1990)

The objective of the model is to find the causal of human error that may lead to accidents and failures. It is widely used in aviation, engineering and healthcare. Although Swiss Cheese Model is a widely used model in identifying human error, it has been subject to some criticisms.(Li \& Thimbleby, 2014). This research centre included that there is lack of supportive models on measuring human error.

\section{Methodology}

\section{Observation}

According to Saunders et al. (2009) observation is suitable for research that concerning with what people do and act. Observation can be defined as a purposeful, systematic and selective method of watching and listening to an interaction or phenomenon as it takes place (Kumar, 2014)

Observation had two main types; participative and non-participative. Participative refers to the researcher that attempt to be fully involved in the lives or activities of subjects and becomes a member of the group organisation or community (Saunder et al., 2009).

In this study, a non-participative observation is adopted by the researcher. This is because the researcher does not want to get involved in the activities of the group but remain a passive observer, watching and listening to the activities and later draw a conclusion. According to Saunders et al. (2009), participative observation is more concerning on determining the frequency of the action and attempt to participate fully in all activities related to the research. Observation is commonly used to identify the root of 'what is going on' in a wide range of social setting and both participative and non-participative has its own advantages and disadvantages.

According to Kumar (2014), this method is appropriate when analysis a situation analysis. Moreover, Kumar (2014) also stressed that studies on ascertain the functions performed by worker is more accurate by using non participative observation method. The author selected non-participative observation as to prevent participant bias and "Hawthorne effect". Besides, the researcher of this study used non-participant observation method to obtain information as to prevent havoc in the workplace. 


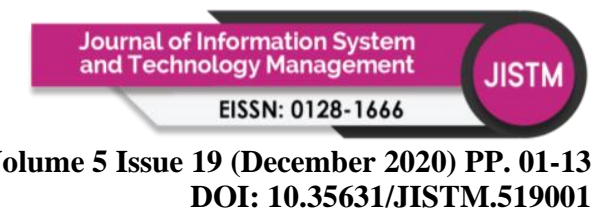

As according to Kumar (2014), there are two easy ways to record the observation result; narrative and categorical. Narrative is used to record a description of the overall interaction whereas categorical recording tends to have choice (few categories) to classify the observation. This study adopted categorical recording

During the observation, a scale was developed in order to rate the various aspects of phenomena. The scale and items are abstracted and adapted from a Rasmussen Skill-RuleKnowledge based Error, Swiss Cheese Model and other researchers' causation of human error in workplace. According to Saunders et al. (2009), one of the treats of observation is 'observer effect'. To access the validity of this observation, the researcher conducted minimal interaction and replication. In order to overcome this effect, he recommended minimal interaction which means sitting in an obtrusive position in a room and avoiding eyes contact with those being observed. Later, replication of observation was adopted in this study. Replication of observation means conducting the same observation with difference observers. The researchers invited a former manufacturing manager with more than 10 years of working experience to be another observer to rank the scale. The reason of involving another observer was to increase the validity of this study and reduces observer effect.

\section{Sampling Criteria}

According to Kumar 2014, a cluster sample is a sampling method that breaks the population into many groups, called clusters. Cluster sampling is based on the ability of the researcher to divide the sampling population into groups. After obtaining a list of manufacturers in Malaysia with approximately more than 39000 registered companies under the Suruhanjaya Syarikat Malaysia (SSM), the author decided to cluster the potential respondents into few levels. In order to reduce the samples, the author used cluster sampling on the types of industries. Basic metal and steel industry, electric and electronically related industry and the rubber and plastic industry were being selected in this study. The Malaysia government mentioned that the these manufactured goods from electric and electronics, basic metals, chemical, petroleum, rubber and plastics are the main source of export income in Malaysia (The Edge, 2018). Later, the author reduced the samples again by clustering the geographical area to Kuala Lumpur, Selangor and Johor. These three states have the most number of SMEs in Peninsular Malaysia compare to the other states (Department of Statistics Malaysia, 2018). However, there are still more than 3000 companies being listed in the directory.

The observation was performed over 9 months at 23 manufacturing industries in year 20172018. The researchers sent more than 3000 invitations of emails to Malaysia manufacturing industries but only 23 manufacturing companies accept the request and there are from (10) Kuala Lumpur, (7) Selangor, and (6) Johor.

\section{Data Analysis}

The analytical approach was inspired by the description of qualitative research. Based on this main understanding, the researcher developed an analytical procedure in three main steps.

The first step was to build a list of potential causes of workplace accident and injuries based on the theoretical perspectives and past literature reviews based on adapted approach. 
This research wanted to investigate the root-cause of workplace accidents. The observers' interpretations were written and formulated, which terms were used when analyze the information inductively.

In step two, the observers will be observed in a more detailed examination on the field and investigate the environments such as temperature, lighting, humidity, layout, and others which were marked as possible causes of workplace accidents and injuries.

Lastly, an overall reading to clarify and validate of the observation was conducted. This was a back-and-forth discussion with all authors and a former manufacturing manager with 10 years working experience

\section{Rigor and Ethic}

The researcher that conducted the field study went an invitation to the manufacturing firms and the participate companies were to anonymize. The data based were labelled as M ((basic metal/metal related companies), E (electric and electronics companies), RP (rubber and plastic related companies). Access to the field was negotiated and approved by the managers.

\section{Results and Discussion}

Based on the observation's findings, 8 main variables were selected; the variables include mental workload, fatigue, machinery or tools, repetition of job, work-rest duration, cycle time, horseplay and working conditions.

All these eight dimensions or variables were tested through content validity by three experts from academics, safety and health department, and management in the manufacturing industry.

Table 3: Observation Result

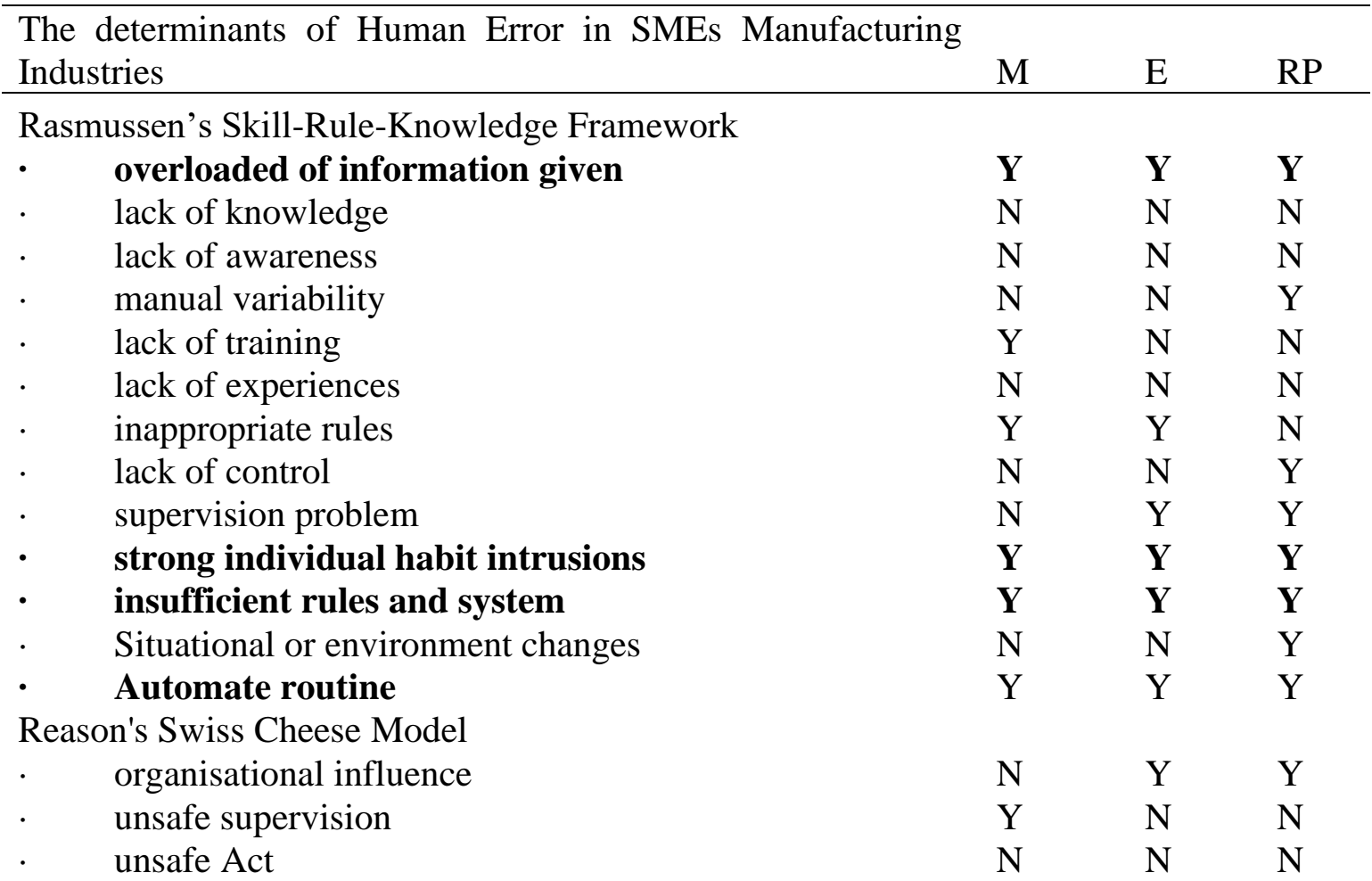


Other possibilities of determinants that cause Human Error

\author{
Machinery/Tools \\ handedness \\ workplace System \\ Leadership problem \\ working condition \\ workplace environment \\ informal communication \\ involving of cycle time \\ lack of work rest
}

\begin{tabular}{lll}
$\mathbf{Y}$ & $\mathbf{Y}$ & $\mathbf{Y}$ \\
$\mathrm{N}$ & $\mathrm{N}$ & $\mathrm{N}$ \\
$\mathrm{N}$ & $\mathrm{Y}$ & $\mathrm{Y}$ \\
$\mathrm{N}$ & $\mathrm{Y}$ & $\mathrm{Y}$ \\
$\mathbf{Y}$ & $\mathbf{Y}$ & $\mathbf{Y}$ \\
$\mathrm{N}$ & $\mathrm{Y}$ & $\mathrm{Y}$ \\
$\mathbf{Y}$ & $\mathbf{Y}$ & $\mathbf{Y}$ \\
$\mathbf{Y}$ & $\mathbf{Y}$ & $\mathbf{Y}$ \\
$\mathbf{Y}$ & $\mathbf{Y}$ & $\mathbf{Y}$ \\
\hline
\end{tabular}

Note: Two categorical (Yes/No) Results based on both observers

Sources: Developed for this study

As stated in the literature review, almost $80 \%$ of workplace accidents are due to human error (Dhillon, 2004). This study discovers the causes of human error in manufacturing industry using observation method. Observation is adopted as Kumar (2014) stressed that studies on ascertain the functions performed by worker is more accurate by using observation method. Based on the findings, the following points are root causes of human error in manufacturing industry which adopted theoretical framework referred Rasmussen's Skill-Rule-Knowledge (SRK) framework, Reason's Generic Error Modelling System (GEMS) and Swiss Cheese Model (SCM). Rasmussen SRK framework is one of the earlier studies in human error and has widely been used by several researchers. Brown (2008) adopted the study and came up with a conclusion that skill-based errors are the most conducted error in the workplace, up to $61 \%$ of the total errors, while $27 \%$ is for rule-based errors, and $11 \%$ is for knowledge-based errors. GEMS modelling was also adopted in this study to show the level of error occurrences in different working environments. Based on GEMS modelling, manufacturing workers are exposed to more skill-based errors, while rule-based errors occur in problem solving. Another model called Swiss Cheese Model was also referred in this study, as it is one of the most popular models regarding human error. With supportive literature review and observation result, the antecedents to human error in manufacturing industry were gathered and, 8 main variables are determined; the variables include mental workload, fatigue, machinery or tools, repetition of job, work-rest duration, cycle time, horseplay and working conditions. All these eight dimensions or variables were tested through content validity by experts from academics, and management in the manufacturing industry.

The public's concern regarding human error has been growing, especially towards impacts of high cost and workplace hazards, such as accident and injuries. This study examines the causes of human error and their implication toward safety and health policy among manufacturing industries. This study testifies the causes of human are caused by 8 variables through nonparticipative observation. This study discovered many informational insights on Malaysian manufacturing industry. Based on the findings of this study, human error in manufacturing industries appears to be a major issue of workplace safety and health. This issue raises concerns among manufacturers because it has led to workplace accidents and injuries. However, by identifying the causes of human error, better guidelines can be given to manufacturers.

This study can encourage them to implement (or improve) a safety and health policy in their respective workplace. With a stronger enforcement of a safety and health policy, human error 


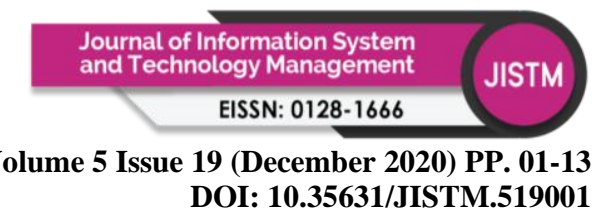

can be reduced drastically, if not prevented entirely. However, the findings show that most manufacturing industry face difficulties when coming up with a proper safety and health policy for their workplace. This study serves as a guideline to manufacturing policy maker. The policy maker can consider several ways such inserting an agenda on enforcement of safety rules during orientation to educate worker to follow the safety and health rules in workplace.

Finally, this empirical study has achieved the objectives. Nevertheless, there are some unavoidable limitations. Accidents and injuries are unpredictable and may occur anytime. Additionally, new rules on safety and health in the workplace may be imposed at any time after this research had been done. This research study was conducted in 2019, including the data collection. Therefore, there might have been new reported cases beyond year 2020 that were not highlighted in the problem statement or literature review.

This study conducted its research based on the top three states in Malaysia with the highest number of SMEs (Selangor, Kuala Lumpur and Johor). The finding of the data cannot represent Malaysia as a whole, especially with the exclusion of East Malaysia (Sabah and Sarawak). Therefore, the interpretation of the result in other regions should be made with cautious discretion. Furthermore, this study used non-participative observation methods and the samples are 23 companies which the samples are relatively small. Besides, the researcher tried to email a DOSH officer for data that can segregate accident rates based on organization sizes (SMEs vs. MNCs) but such data is not available. There is no data from DOSH or SOCSO that shows accident and injury rates based on the organization 's size.

\section{Conclusion}

In a nutshell, this study had achieved all the objectives. This empirical study examines the antecedents of human errors and with all the supportive literature review. With the supportive analysis, it helps manufacturer and policy makers to determine the importance of human error in workplace. For future study, it is recommended to impose more training, seminars, conferences to manufacturing owners and creates more awareness too public regarding safety and health issues. Besides, future study can focus on other industry such as banking as the tendency of making mistake is high. Other research method can also be considered to analyse the human error in manufacturing industry.

\section{References}

Benedyk, R., \& Minister, S. (1998). Applying the BeSafe method to product safety evaluation The legal requirement for evaluation of safety. Applied Ergonomics.

Brown, A. (2008). An Overview of Human Error. Recovery- Oriented Computing. http://roc.cs.berkeley.edu/294fall01/slides/human-error.pdf

Carbon, C. C., \& Albrecht, S. (2012). Bartlett's schema theory: The unreplicated "portrait d'homme" series from 1932. Quarterly Journal of Experimental Psychology. https://doi.org/10.1080/17470218.2012.696121

Dekker, S. (2013). The field guide to understanding human error. In The Field Guide to Understanding Human Error.

Dhillon, B. S. (2004). Reliability, quality, and safety for engineers. In Reliability, Quality, and Safety for Engineers. https://doi.org/10.1198/tech.2006.s360

DiDomenico, A., \& Nussbaum, M. A. (2008). Interactive effects of physical and mental workload on subjective workload assessment. International Journal of Industrial Ergonomics. https://doi.org/10.1016/j.ergon.2008.01.012 


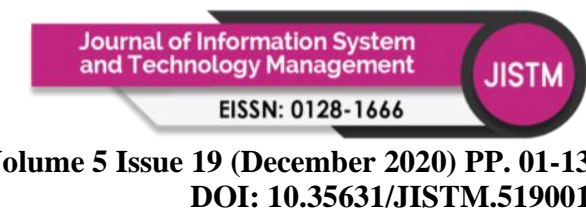

DOSH. (2020). Occupational Accident Statistics. Department of Occupational Safety and Health, Misniter of Human Resource Malaysia. https://www.dosh.gov.my/index.php/list-of-documents/statistics/occupationalaccident-statistics

Ellis, H. (1900). A Study of Lapses (Monograph Supplement, Psychological Review ). By H. Heath Bawden, A.M. New York: Macmillan and Co. 1900. Pp. 122. . Journal of Mental Science. https://doi.org/10.1192/bjp.46.195.796

Emir Zainul. (2018, November). MoF: Malaysian manufacturing sector to grow 4.7\% y-o-y in 2019. The Edge Market. https://www.theedgemarkets.com/article/mof-malaysianmanufacturing-sector-grow-47-yoy-2019

Gould, S. J. (1987). Freudian slip. Natural History.

Karim, M. A., Smith, A. J. R., Halgamuge, S. K., \& Islam, M. M. (2008). A comparative study of manufacturing practices and performance variables. International Journal of Production Economics. https://doi.org/10.1016/j.ijpe.2007.07.005

Kumar, R. (2014). Research Methodology: a Step by Step guidefor beginners. In SAGE Open. Li, Y., \& Thimbleby, H. (2014). Hot cheese: A processed Swiss cheese model. Journal of the Royal College of Physicians of Edinburgh. https://doi.org/10.4997/JRCPE.2014.205

Liu, H., Hwang, S. L., \& Liu, T. H. (2009). Economic assessment of human errors in manufacturing environment. Safety Science, 47(2), 170-182. https://doi.org/10.1016/j.ssci.2008.04.006

Molloy, G. J., \& O’Boyle, C. A. (2005). The SHEL model: A useful tool for analyzing and teaching the contribution of human factors to medical error. In Academic Medicine. https://doi.org/10.1097/00001888-200502000-00009

Rasmussen, J. (1983). Skills, Rules, and Knowledge; Signals, Signs, and Symbols, and Other Distinctions in Human Performance Models. IEEE Transactions on Systems, Man and Cybernetics. https://doi.org/10.1109/TSMC.1983.6313160

Ratnasingam, J., Ioras, F., \& Bennet, M. (2010). Malaysian wooden furniture industry: Study of safety standards, compliance and consequential implications. International Wood Products Journal. https://doi.org/10.1179/002032010X12759166444841

Reason, J. (1990). The contribution of latent human failures to the breakdown of complex systems. Philosophical Transactions of the Royal Society of London. Series B, Biological Sciences. https://doi.org/10.1098/rstb.1990.0090

Reason, James. (2000). Human error: Models and management. In British Medical Journal. https://doi.org/10.1136/bmj.320.7237.768

Reason, James. (2016). Organizational accidents revisited. In Organizational Accidents Revisited. https://doi.org/10.4324/9781315562841

Reason, James. (2017). The human contribution: Unsafe acts, accidents and heroic recoveries. In The Human Contribution: Unsafe Acts, Accidents and Heroic Recoveries. https://doi.org/10.1201/9781315239125

Ruckart, P. Z., \& Burgess, P. A. (2007). Human error and time of occurrence in hazardous material events in mining and manufacturing. Journal of Hazardous Materials, 142(3), 747-753. https://doi.org/10.1016/j.jhazmat.2006.06.117

Sai, S. M., Halim, Z. A., \& Said, F. (2012). Workplace injuries in Malaysian Manufacturing Industries. Journal of Occupational Safety And Health.

Saunders, M., Lewis, P., \& Thornhill, A. (2009). RM Saunders. www.pearsoned.co.uk

Saurin, Tarcisio A., Formoso, C. T., \& Cambraia, F. B. (2004). A Human Error Perspective of Safety Planning and Control. 12th Annual Conference of the International Group for Lean Construction. 
Saurin, Tarcisio Abreu, Formoso, C. T., \& Cambraia, F. B. (2008). An analysis of construction safety best practices from a cognitive systems engineering perspective. Safety Science. https://doi.org/10.1016/j.ssci.2007.07.007

Surienty, L., Hong, K. T., Kee, D., \& Hung, M. (2011). Occupational Safety and Health (Osh) in Smes in Malaysia : a. Journal of Global Enterprenueship, 1(1), 65-75.

The Performance of States economy 2017. (2018). Statistis, Department of Malaysia. https://www.dosm.gov.my/v1/index.php?r=column/cthemeByCat\&cat=449\&bul_id= L25EUXQxbWdBaEVoWXU5aTFQWUpNdz09\&menu_id=TE5CRUZCblh4ZTZM ODZIbmk2aWRRQT09

Williamson, A. M., \& Feyer, A. M. (2000). Moderate sleep deprivation produces impairments in cognitive and motor performance equivalent to legally prescribed levels of alcohol intoxication. Occupational and Environmental Medicine. https://doi.org/10.1136/oem.57.10.649

Yeow, J. A., Khan, M. K. B. J., \& Ng, P. K. (2017). Enforcement of safety and health policy reduces human error in SMEs in the manufacturing industry. Advanced Science Letters. https://doi.org/10.1166/asl.2017.10124

Yeow, J. A., Ng, P. K., Tan, K. S., Chin, T. S., \& Lim, W. Y. (2014). Effects of Stress, Repetition, Fatigue and Work Environment on Human Error in Manufacturing Industries. Journal of Applied Sciences. https://doi.org/10.3923/jas.2014.3464.3471

Zakaria, N. H., Mansor, N., \& Abdullah, Z. (2012). Workplace Accident in Malaysia: Most Common Causes and Solutions. Business and Management Review. 